\title{
Prevalence, sociodemographic determinants and self-reported reasons for hysterectomy in India
}

\author{
Chander Shekhar ${ }^{1 *}$, Balram Paswan² and Abhishek Singh ${ }^{3}$
}

\begin{abstract}
Background: Evidence of hysterectomy in India is limited mainly due to lack of information in large-scale nationally representative health surveys. In 2015-16, the fourth National Family Health Survey (NFHS-4) - a cross-sectional survey - collected for the first time direct information on hysterectomy and self-reported reasons for undergoing the procedure among women in the reproductive age group. This paper examines the prevalence and determinants of hysterectomy in India among women aged 30-49 years in 29 states and seven union territories (UTS) of India using the NFHS-4 dataset.
\end{abstract}

Methods: Percentage weighted by sampling weights was used for estimating the prevalence of hysterectomy. The paper used crosstabulations and percentage distributions to estimate the prevalence of hysterectomy across different socioeconomic backgrounds and reasons for undergoing hysterectomy respectively. A multivariate binary logistic regression model was also used to find statistically significant determinants of hysterectomy.

Results: In India as a whole, $6 \%$ of women aged 30-49 years had undergone a hysterectomy. The percentage of women who had undergone the procedure was found to vary considerably across the states and the UTs (from a minimum of $2 \%$ in Lakshadweep to a maximum of $16 \%$ in Andhra Pradesh). A noticeable fact that emerged was that the majority of the hysterectomies were performed in the private sector except in the northeast region. Years of schooling, caste, religion, geographic region, place of residence, wealth quintiles, age, parity, age at first cohabitation, marital status, and body mass index of women were found to be the sociodemographic determinants statistically associated with hysterectomy in India. The reasons reported frequently for hysterectomy were excessive menstrual bleeding/pain (56\%), followed by fibroids/cysts (20\%).

Conclusion: The percentage and likelihood of undergoing hysterectomy are relatively high among women from older age groups (45-49), those who reside in rural areas, those without schooling, those who are obese, those having high parity, those with a low age at first marriage, and those who reside in the eastern and southern parts of India. The policy implication of these findings is that the reproductive health program managers should ensure regular screening and timely treatment of the problems resulting in hysterectomy.

Keywords: Hysterectomy, Prevalence, Sociodemographic, Determinants, Self-reported reasons, India

\footnotetext{
* Correspondence: buddhab@iips.net; shekhariips@rediffmail.com

${ }^{1}$ Department of Fertility Studies, International Institute for Population

Sciences (IIPS), Mumbai, India

Full list of author information is available at the end of the article
}

(C) The Author(s). 2019 Open Access This article is distributed under the terms of the Creative Commons Attribution 4.0 International License (http://creativecommons.org/licenses/by/4.0/), which permits unrestricted use, distribution, and reproduction in any medium, provided you give appropriate credit to the original author(s) and the source, provide a link to the Creative Commons license, and indicate if changes were made. The Creative Commons Public Domain Dedication waiver (http://creativecommons.org/publicdomain/zero/1.0/) applies to the data made available in this article, unless otherwise stated. 


\section{Plain English summary}

Hysterectomy is a surgery that involves partial or complete removal of the uterus of a woman. In India, nationally representative reliable statistics are rarely available on this important aspect of women's health. The fourth round of the National Family and Health Survey (NFHS-4) canvassed, for the first time, a battery of direct questions on hysterectomy and the reasons for undergoing it.

This paper used the NFHS-4 dataset to estimate the prevalence of hysterectomy in the states and the Union Territories in India by different socioeconomic backgrounds of women. It also shows the statistical significance and likelihood of women from different socioeconomic backgrounds undergoing a hysterectomy.

Six percent of women in the age group 30-49 years have undergone a hysterectomy in India as a whole. Women who come from the rural areas, had no schooling, have a body mass index more than or equal to 25 $\mathrm{kg} / \mathrm{m} 2$, belong to a high wealth quintile household, have higher parity, had a low age at marriage, and are from eastern and southern India are more likely to undergo a hysterectomy. Among the main reasons for hysterectomy reported by women aged 30-49 years are excessive menstrual bleeding/pain (56\%), fibroids/cysts (20\%), and uterine disorder, that is, rupture $(14 \%)$ and uterine prolapse (8\%).

Translating the prevalence of hysterectomy into absolute numbers for the year 2016, there were about 10 million hysterectomized women (aged 30-49 years) living in India. This huge number may further increase if reasons for hysterectomy are not diagnosed and treated effectively at an early stage. Policymakers and program managers must ensure timely and quality reproductive health services up to the primary healthcare level.

\section{Introduction}

Hysterectomy is a surgical operation whereby the uterus of a woman is removed. There are different types of hysterectomy such as partial, total and radical hysterectomy. In case of partial hysterectomy, the upper part of the uterus is removed but the cervix is left in place. In total hysterectomy, the whole uterus, including the cervix, is removed. And in radical hysterectomy, the whole uterus, the tissue on the sides of the uterus, the cervix, and the top part of the vagina are removed. Radical hysterectomy is generally suggested to women in case of cancer.

Hysterectomy is primarily done to save women from uterus-related life-threatening problems and for a better and healthy life. It is done for different gynecological conditions that include uterine fibroids that cause pain, bleeding, or other problems; uterine prolapse; cancer of the uterus, cervix or ovaries; endometriosis; abnormal vaginal bleeding; chronic pelvic pain; or Adenomyosis.
In case of noncancerous situations, it is considered only after all other treatment approaches have failed or have been exhausted [1].

A number of studies have looked at the socioeconomic, demographic, and residence related correlates of hysterectomy in different settings, including India [2-8]. A cohort study examined the risk factors for peripartum hysterectomy. Using data from 193 hospitals from 21 countries from Africa, Asia, Europe, and the Americas, the study concluded that placenta praevia/accreta is associated with a higher risk of peripartum hysterectomy. Women in Asia had a higher hysterectomy incidence (7\%) than women in Africa (5\%) (adjusted odds ratio: 1.2, 95\%confidence interval (CI): 0.9-1.7). The other risk factors the study found were advanced maternal age, caesarean section, and giving multiple births in Asia [7].

A few studies have also examined other risk factors for hysterectomy. A study by Whiteman et al. (2006) reported that primary caesarean deliveries, repeat caesarean deliveries, vaginal birth after caesarean, and multiple births were independently associated with an increased risk for peripartum hysterectomy [9]. Dharmalingam, Pool and Dickson (2000), using nationally representative data from New Zealand, found that older women, women who experienced foetal loss, women of higher parity, married women, women who used intrauterine devices (IUDs) and pills, and women with tubal sterilization were at a high risk for hysterectomy [3]. In rural China, women at a higher age (40 years and above), those with a higher body mass index, and those who had experienced loss of a child previously were at a higher risk for hysterectomy [10].

The knowledge regarding hysterectomies in India is limited partly due to lack of information in large-scale national representative surveys. Two mixed method studies in a low income setting in Gujarat in India found that women with low income, those at a higher age, rural women, married women, and women with more surviving children were at a higher risk for hysterectomy. The study revealed that the mean age at hysterectomy was 36 years and that the majority of the women had used private health facilities for hysterectomies $[5,6]$.

A study in three villages of Panchkula district in Haryana revealed that the prevalence of hysterectomy was more in women above the age of 35 years. Excessive menstrual bleeding was the main indication for hysterectomy $(52 / 70 ; 74 \%)$; uterine prolapse and fibroids were the other indications [11]. In an urban setting of district Moradabad in Uttar Pradesh, a study found that women who had their first pregnancy before the age of 20 years had a 2.5 times higher chance of undergoing a hysterectomy than those who first became pregnant at age 20 years or later [4]. 
A study was recently carried out using secondary data from the fourth round of the district level household survey (2012-13) done among married women aged 1549 years in 21 states and UTs [8]. It found that the likelihood of hysterectomy was 1.9 times higher among women belonging to households having a health insurance, which raised suspicions about the misuse of the procedure. It found that the prevalence of hysterectomy across 21 states and UTs ranged from $0.2 \%$ to $6.3 \%$. A major limitation of this study was the national representation since the 21 states covered in the survey represented only about $52 \%$ of the total married women aged 15-49 years in India. The other major limitations included lack of information on the age at hysterectomy, type of facility where the procedure was done, and reasons for hysterectomy.

A study by Radha et al. (2015) in Tirupati city of Andhra Pradesh found that the common indications for hysterectomy were fibroids (45\%), menorrhagia (31\%), prolapse (10\%), endometrial hyperplasia (5\%), cervical dysplasia (3\%), and chronic pelvic inflammatory disease (5\%) [12]. In another recent study, pelvic organ prolapse was the most common indication for hysterectomy, while uterine fibroids, dysfunctional uterine bleeding, ovarian mass, chronic pelvic inflammatory disease, and cervical intraepithelial neoplasia were the other indications [13]. Pandey et al. (2014) did a hospital based study and found that the most common indication for hysterectomy was symptomatic uterine fibroid (40\%), followed by prolapse $(16 \%)$, and that the overall complication rate was $8.5 \%$ [14].

Uikey, Wankhede and Tajne (2018) found that the commonest indication for hysterectomy was fibroid uterus $(65.33 \%)$ in Maharashtra state of India. They concluded that in a developing country like India with poor healthcare resources, non-descent vaginal hysterectomy offers a distinctive advantage over abdominal and laparoscopic assisted vaginal hysterectomy and should be the route of choice for benign uterine conditions [15].

Some researchers and activists have questioned the unnecessary hysterectomies being carried out in some parts of India for commercial gains rather than medical necessity, and at a much younger age of women in states like Andhra Pradesh [16-19]. There has also been considerable debate concerning the efficacy of elective hysterectomy as reproductive health problems of women do not end there [20]. Once a hysterectomy has been done, many health complications start such as: i) early onset of menopause, ii) higher risk of cardiovascular disease, iii) higher risk of stroke, iv) urinary incontinence, v) loss of sexual desire, and vi) other health problems $[5,6]$.

A study done by Verma, Singh and Kulshrestha (2016), among patients in a north Indian city, justified hysterectomy medically only when the histopathological examination (HPE) report is compatible with the preoperative diagnosis and recommended that the HPE should be done and analysed for all hysterectomy specimens. It found that uterovaginal prolapse (38\%) was the most common preoperative indication, while fibroid uterus $(26 \%)$ was the commonest indication for abdominal hysterectomy. Other common indications were dysfunctional uterine bleeding (10\%) and ovarian mass $(8 \%)$ [21].

Most of the literature available on hysterectomies is from studies conducted in the developed world or from clinic based samples. The literature available with regard to India is limited in nature and scope. To our knowledge, a population based study that can cover India as a whole has not yet been conducted on a large-scale nationally representative dataset. It is important to mention here that the National Family and Health Survey in its fourth round (NFHS-4) collected, for the first time, direct information on hysterectomy from women in the reproductive age group. Having noted the gaps in the existing literature on hysterectomy in India and given the availability of a recent large-scale population based nationally representative dataset, the present study investigated the prevalence and determinants of hysterectomy in women aged 30-49 years in India. We restricted our analysis to women aged $30-49$ years because previous studies have shown that women of higher age are at a high risk of hysterectomy [2, 3, 5, 6, 10, 22].

This paper seeks answers to the following questions: (i) what is the prevalence of hysterectomy in different sociodemographic subgroups of Indian women aged 3049? ii) do women from different sociodemographic subgroups carry significantly different risks to undergo hysterectomy? and (iii) what are the variations across states/ UTs in self-reported reasons for seeking hysterectomy? Therefore, the specific objectives of this paper are: i) to understand the prevalence of hysterectomy among women aged 30-49 years at the national, state, UT and regional levels in India, ii) to examine the sociodemographic determinants of hysterectomy, and iii) to examine the reasons reported by women for hysterectomy.

\section{Materials and methods}

\section{Study setting and participants}

The dataset used in this paper has been taken from the Demographic and Health Survey, popularly known as the National Family and Health Survey (NFHS-4), conducted during 2015-16. The survey was conducted by the International Institute for Population Sciences (IIPS), Mumbai, under the aegis of the Ministry of Health \& Family Welfare, Government of India. The main objectives of the survey were to provide the estimates of fertility, mortality, family planning, maternal and child health indicators, domestic violence, women's autonomy, 
and non-communicable diseases and associated risk factors. The NFHS-4 collected information from 699,686 women aged 15-49 years, including 340,127 women aged 30-49 years, from 29 states and seven UTs of India [23].

The survey adopted a two-stage design in both rural and urban areas. In the rural areas, villages were selected in the first stage using the probability proportional to size scheme (PPS). Twenty-two households were chosen from the earmarked villages using systematic sampling in the second stage. In the urban areas, census enumeration blocks (CEBs) were selected in the first stage using PPS, and 22 households were selected in the second stage using systematic sampling. Women (15-49) residing in the selected households were interviewed with a $97 \%$ response rate. Only women in the age bracket $30-49$ years were considered as the unit of analysis. The data analysis is secondary and remains mainly descriptive in nature.

As per the survey protocol of NFHS-4, ethical approval was sought from the IIPS Institutional Ethical Review Board with certificate ref. no./IRB/NFHS-4/01_1/2015.

\section{Outcome and independent variables}

The outcome variable used in the present analysis is hysterectomy. The NFHS-4 asked women various questions related to hysterectomy. The first question asked was: "When did your last menstrual period start?" Among the several answers to this question, one of the options was "Has had hysterectomy". The direct question on hysterectomy canvassed was "Some women undergo an operation to remove the uterus. Have you undergone such an operation?" If the answer was yes, women were asked further questions regarding the timing and place of and the reason for the hysterectomy.

The independent variables, their categorization and their definitions are given in the following table.

\begin{tabular}{|c|c|c|}
\hline $\begin{array}{l}\text { Independent } \\
\text { variable }\end{array}$ & Definition & Categories \\
\hline Age & $\begin{array}{l}\text { Biological age of women } \\
\text { respondent }\end{array}$ & $30-34 ; 35-39 ; 40-44 ; 45-49$ \\
\hline $\begin{array}{l}\text { Women's } \\
\text { education }\end{array}$ & $\begin{array}{l}\text { Educational attainment of } \\
\text { women depending on } \\
\text { years of schooling }\end{array}$ & $\begin{array}{l}\text { No Schooling (0 years of } \\
\text { schooling); Primary } \\
\text { complete ( } 5 \text { years of } \\
\text { schooling); Secondary } \\
\text { complete (6-12 years of } \\
\text { schooling); Higher (13 } \\
\text { years and above } \\
\text { schooling) }\end{array}$ \\
\hline Caste/Tribe & $\begin{array}{l}\text { Scheduled Caste/Tribe, } \\
\text { Other Backward Classes as } \\
\text { defined in the Indian } \\
\text { constitution for the socially } \\
\text { and economically deprived } \\
\text { sections of the society }\end{array}$ & $\begin{array}{l}\text { Scheduled caste; } \\
\text { Scheduled tribe; Other } \\
\text { Backward Class; Others } \\
\text { (does not belong to any } \\
\text { of the above three } \\
\text { groups) }\end{array}$ \\
\hline Religion & $\begin{array}{l}\text { Religion in which the } \\
\text { respondent believes }\end{array}$ & $\begin{array}{l}\text { Hindu; Muslim (Islam); } \\
\text { Christian; Sikh; Buddhist/ } \\
\text { neo-Buddhist; Other }\end{array}$ \\
\hline
\end{tabular}

\section{Outcome and independent variables (Continued)}

\begin{tabular}{lll}
$\begin{array}{l}\text { Independent } \\
\text { variable }\end{array}$ & Definition & Categories \\
\hline Residence & $\begin{array}{l}\text { Place where the } \\
\text { respondent usually lives }\end{array}$ & $\begin{array}{l}\text { (Other than the above } \\
\text { four religions) }\end{array}$ \\
Wealth Index & $\begin{array}{l}\text { Household wealth index } \\
\text { created by using scores of } \\
\text { possession of certain goods } \\
\text { and assets and classified in } \\
\text { quintiles. Score moving } \\
\text { from lowest to highest } \\
\text { means household moving } \\
\text { from poor to rich category. }\end{array}$ & \\
\hline
\end{tabular}

Body Mass $\quad \mathrm{BMI}$ is Weight (in kilogram) $\mathrm{BMl}<25 \mathrm{~kg} / \mathrm{m}^{2} ; \mathrm{BMI}>=$ Index (BMI) of of a woman divided by the $25 \mathrm{Kg} / \mathrm{m}^{2}$; BMI Not women square of height (in meters) Available (could not be of women; measured)

Marital Status Current marital status of Currently Married; Widow; women; Others includes Others divorce, separated, and living together without marriage

Age at first Age (in years) at which cohabitation woman started living with spouse

Parity Total no. of children ever $\quad 0 ; 1-2 ; 3$ and above born to women

Region Region comprising a group North; Central; East; of states, depending upon Northeast; West; South the geographical region and the sociocultural milieu these states fall in ${ }^{1}$

Time since No. of years gone by after a Less than $3 ; 3-5 ; 6-10 ; 10$ hysterectomy woman underwent a and above years

(in years) hysterectomy

Place of Place where a woman Public health facilities; hysterectomy underwent a hysterectomy; Private health facilities it is divided into two groups: public and private health facilities*

*India's health system can be easily divided into public and private health systems. In general, both public and private health systems can be further categorised into a three-tier health care system (primary, secondary, tertiary). Primary and secondary public health care system is predominantly located in rural areas. On the other hand, private and tertiary public health care system is mainly located in urban areas. The socioeconomically poor and those belonging to the rural strata of the Indian society are primarily dependent on the public health system in seeking all types of healthcare services. Sometimes, inaccessibility, inefficiency, and quality issues with the public healthcare system force people to go to the private providers, pushing them into poverty due to the necessity of having to pay a heavy out-of-pocket expenditure even for basic primary healthcare needs

\footnotetext{
${ }^{1}$ North (Chandigarh, Delhi, Haryana, Himachal Pradesh, Jammu \& Kashmir, Punjab, Rajasthan, Uttarakhand); Central (Chhattisgarh, Madhya Pradesh, and Uttar Pradesh); East (Bihar, Jharkhand, Odisha, West Bengal); Northeast (Arunachal Pradesh; Assam, Manipur, Meghalaya, Mizoram, Nagaland, Sikkim, Tripura); West (Dadra \& Nagar Haveli, Daman \& Diu, Goa, Gujarat, Maharashtra); South (Andaman \& Nicobar Island, Andhra Pradesh, Karnataka, Kerala, Lakshadweep, Puducherry, Tamil Nadu, Telangana)
} 
Crosstabulation, Chi-square, and a multivariate logistic regression (Backward Stepwise (Likelihood Ratio)) were used to analyse the data. The Omnibus Tests of Model Coefficients is used to test whether the new model got improved over the base model. The test uses Chi-square values to test weather -2Log-likelihood has significantly improved from the base to the final mode. To test the difference in the estimated median for the selected backgrounds, the K-independent sample non-parametric test was used. Appropriate sampling weights were used in the calculation of percentages, percent distributions, and prevalence. The details of the sampling weights are given in the national report [23]. The analysis was carried out in statistical package for social sciences (SPSS) 17.0. We also used geographical information system (GIS) to prepare a thematic map.

\section{Results}

\section{Prevalence and geographical pattern of hysterectomy in} India

The proportion of women who have undergone a hysterectomy is not low in India, as is evident from the latest empirical data of the NFHS-4. The proportion of women who have undergone a hysterectomy was $6 \%$ among women aged 30-49 (Table 1).

Figure 1 shows that the percentage of hysterectomies carried out among women aged 30-49 was the highest in Andhra Pradesh, which at $16 \%$ is much higher than the national level of $6 \%$. The state of Telangana ranked second, where $14 \%$ women aged 30-49 had undergone hysterectomies, followed by Bihar (11\%), Gujarat (8\%), and Tamil Nadu (6\%). Among UTs, Dadra \& Nagar Haveli showed the highest prevalence of hysterectomy (7\%), whereas Lakshadweep (2\%) had the lowest prevalence. There is a considerable variation in the proportion of women aged 30-49 undergoing hysterectomy by different geographical regions in India.

\section{Contrasts in median age of hysterectomy in India}

Figure 2 provides the median age (in years) of women at hysterectomy in India and variations across residence, education, and wealth index. It shows that half of those who reported to have had a hysterectomy had undergone it by the age of 34 years among women aged $30-49$ years. The median age at hysterectomy was about 2 years higher among urban women (35.3 years) than rural women (33.7 years). Women with no schooling had a hysterectomy at a younger median age (34 years) than women educated up to 12 or more years of schooling (38.4 years). A clear contrast appeared between women belonging to the lowest and the highest wealth quintile households, with the median age at hysterectomy of women belonging to the lowest quintile being 2.4 years younger than that of women from households in the highest wealth quintile. All the median ages for hysterectomy across residence, educational and household wealth index categories, shown in Fig. 2, were found significantly different at $p<0.000$ when Kindependent sample non-parametric test was applied.

\section{Socioeconomic differentials in hysterectomy in India}

Table 1 presents the percentage of women aged 30-49, who have had a hysterectomy, by socioeconomic and demographic characteristics. A considerable variation by socioeconomic and demographic characteristics of women is observed in the risk of hysterectomy. The level of hysterectomy increases with an increase in age. About $3 \%$ of women aged 30-34 reported having undergone a hysterectomy; this proportion increased to $5 \%$ among women aged 35-49, $8 \%$ among women aged $40-44$, and to $11 \%$ among women aged $45-49$. The risk of hysterectomy was higher among women with no schooling. Around $8 \%$ of women with no schooling had a hysterectomy compared with only $3 \%$ women with higher education. Seven per cent women aged 30-49 with "primary complete" level of education and $5 \%$ women with "secondary complete" level of education had undergone a hysterectomy in the NFHS-4.

A higher proportion of other backward class women (7\%) reported having undergone a hysterectomy compared with $6 \%$ women belonging to other than scheduled castes, scheduled tribes, and other backward class. Among scheduled caste women, the prevalence was $6 \%$, and among scheduled tribe women, it was $5 \%$. The percentage of hysterectomized women was the highest among Hindu women (6\%), followed by Christian women, and the lowest among Buddhist/Neo Buddhist women (3\%). Rural women (7\%) were at a higher risk of hysterectomy compared with urban women (5\%). A smaller proportion of women (5\%) from the lowest wealth quintile had undergone hysterectomy compared with $7 \%$ from the third and fourth quintiles. In percentage, more women $(8 \%)$ with higher BMI $\left(\mathrm{BMI}>=25.0 \mathrm{~kg} / \mathrm{m}^{2}\right.$ ) were found to be at higher risk of undergoing hysterectomy compared with only around 6 $\%$ women with BMI $<25.0 \mathrm{~kg} / \mathrm{m}^{2}$ (Table 1 ).

Table 1 clearly shows that compared with women in the other category (3\%), a higher proportion (7\%) of widows had undergone hysterectomy, followed by currently married women (6\%). The study finds that the percentage of hysterectomized women was high (10\%) among women who had started cohabitation at a younger age, particularly below age 15 years. In terms of parity, the proportion of hysterectomized women increased with increase in the parity of a woman, standing at $7 \%$ among women with third or higher order parity. 
Table 1 Percentage of women (30-49) undergone hysterectomy by sociodemographic and geographical background in India, NFHS (2015-16)

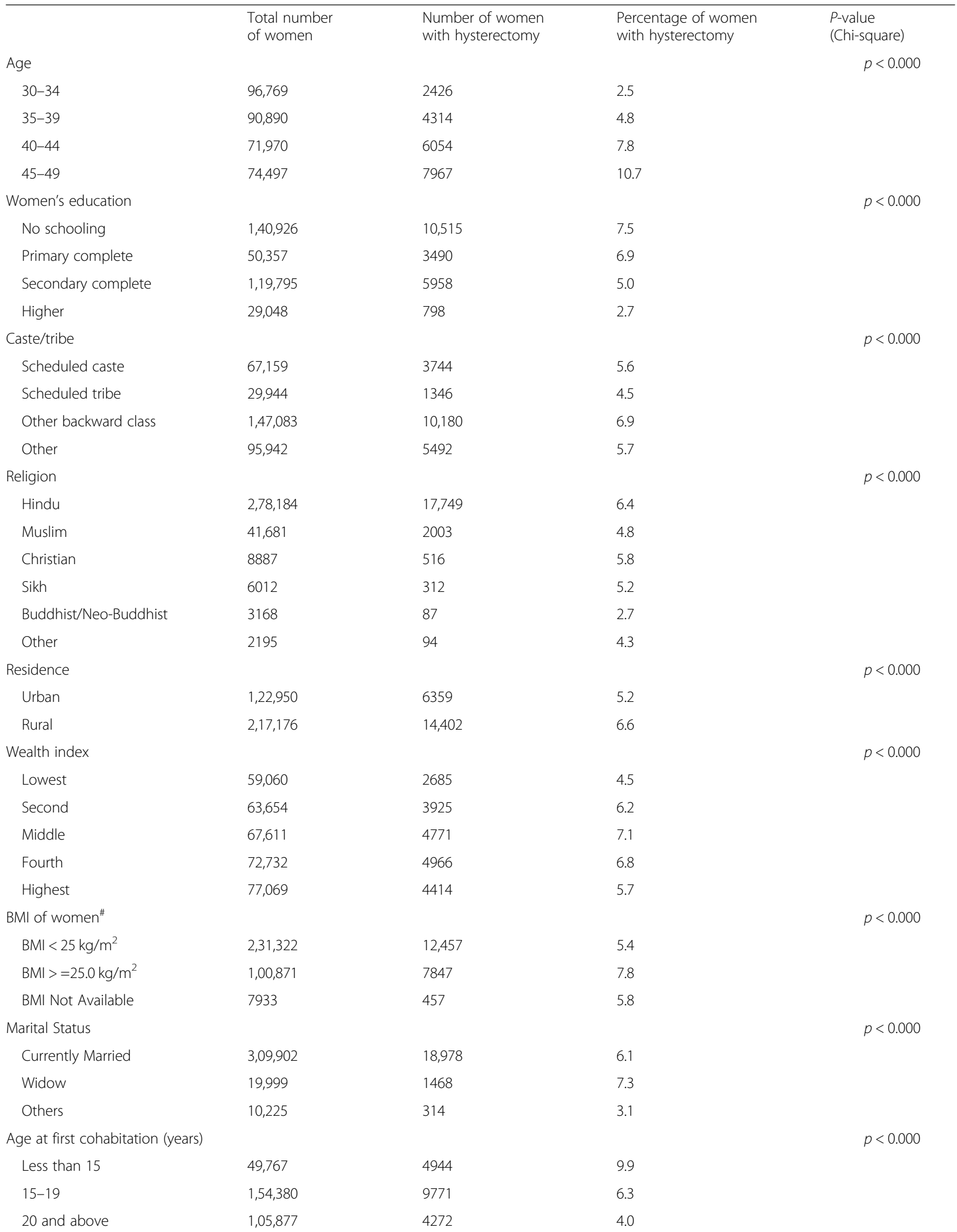


Table 1 Percentage of women (30-49) undergone hysterectomy by sociodemographic and geographical background in India, NFHS (2015-16) (Continued)

\begin{tabular}{|c|c|c|c|c|}
\hline Not Applicable/available & 30,102 & 1774 & 5.9 & \\
\hline Parity & & & & $p<0.000$ \\
\hline 0 & 15,729 & 403 & 2.6 & \\
\hline $1-2$ & $1,45,988$ & 8166 & 5.6 & \\
\hline 3 and above & $1,78,408$ & 12,191 & 6.8 & \\
\hline State/union territory & $\begin{array}{l}\text { Total number of } \\
\text { women }\end{array}$ & $\begin{array}{l}\text { Number of women } \\
\text { with hysterectomy }\end{array}$ & $\begin{array}{l}\text { Percentage of women } \\
\text { with hysterectomy }\end{array}$ & P-value (Chi-square) \\
\hline Region & & & & $p<0.000$ \\
\hline North & 45,375 & 1955 & 4.3 & \\
\hline Central & 73,527 & 3767 & 5.1 & \\
\hline East & 73,111 & 4685 & 6.4 & \\
\hline Northeast & 12,126 & 252 & 2.1 & \\
\hline West & 50,723 & 3022 & 6.0 & \\
\hline South & 85,265 & 7080 & 8.3 & \\
\hline India & $3,40,127$ & 20,761 & 6.1 & \\
\hline
\end{tabular}

Table 1 also provides regional variations in the level of hysterectomy in India. The South (8\%) and East (6\%) regions show a prevalence of hysterectomy above the national level. The level for the North, Central and West regions turns out to be slightly lower than the national average (6\%), whereas the least proportion of women undergoing hysterectomy was found in the Northeast region $(2 \%)$.

Table 2 reveals the average number of years passed between when a woman underwent a hysterectomy and the survey date. Forty-six percent women had completed seven or more years since the operation had been done, followed by $31 \%$ who had passed less than 4 years. The rest of the $23 \%$ women had completed between four and 6 years.

\section{Regional variations in type of health institutions where hysterectomy was sought}

Women who had hysterectomies were further asked, "Where was this operation performed?" A little less than one-third $(32 \%)$ of hysterectomies in India were done in public health facilities and the rest in private health facilities at the national level (Table 2). It is important to mention that the private health facilities also include a very small proportion (nearly $1 \%$ ) of nongovernmental organizations (NGOs) or not-forprofit trusts.

The pattern in the north and the northeast regions was quite different from the country as a whole (data not shown). Sixty-one per cent of hysterectomies in the northeast region were done in public institutions, followed by $39 \%$ in the north. The utilisation of the public sector was the highest in Assam (64\%), followed by Jammu and Kashmir (62\%). None of the women in Lakshadweep had utilised public sector facilities. The utilisation of the private sector was more than $70 \%$ in Jharkhand (72\%), Uttar Pradesh (76\%), and Bihar (82\%) [data not shown but can be provided on request].

\section{Results from multivariate logistic regression analysis}

Table 3 shows the odds ratio (OR) from the multivariate logistic regression that was run to examine the likelihood of a woman undergoing hysterectomy (dependent variable) belonging to given sociodemographic background characteristics (independent variables). Woman's age was found to be statistically associated with increase in the risk for hysterectomy. For example, women aged 45-49 were 3.8 times as likely as women aged 30-34 to have undergone a hysterectomy. Likewise, women aged 40-44 were 2.8 times more likely than women aged 30-34 to have undergone a hysterectomy. Woman's schooling was negatively associated with hysterectomy. Women with more years of schooling were less likely to have undergone a hysterectomy compared with women with no schooling. For example, women with higher education were about 0.4 times less likely to have had a hysterectomy compared with women with no schooling. Women with "secondary complete" level of education were about 35\% less likely to have had a hysterectomy compared with women with no schooling. Caste was also found to be associated with hysterectomy. Compared with women from scheduled castes, women from scheduled tribes were less likely to have had a hysterectomy. However, women from other backward classes and other castes were more likely to have 


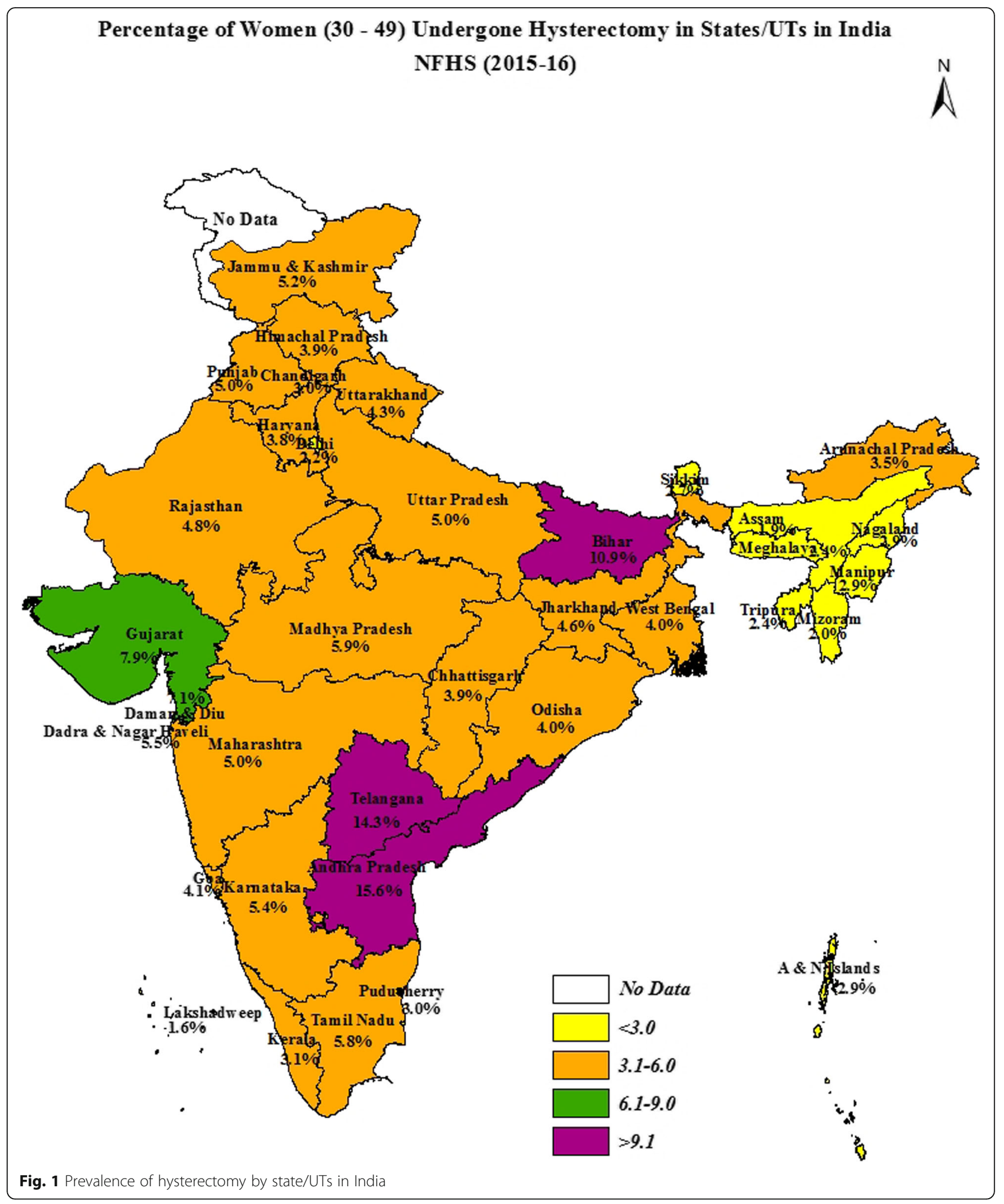

undergone the operation than their scheduled caste counterparts. Muslim (OR:0.708, 95\%CI[0.673-0.744]) and Buddhist/Neo-Buddhist (OR:0.499, 95\%CI[0.400$0.622]$ ) women were less likely to have had a hysterectomy compared with Hindu women. On the other hand, Sikh women (OR:1.173, 95\%CI[1.035-1.331]) were more likely to have undergone a hysterectomy compared with Hindu women. 


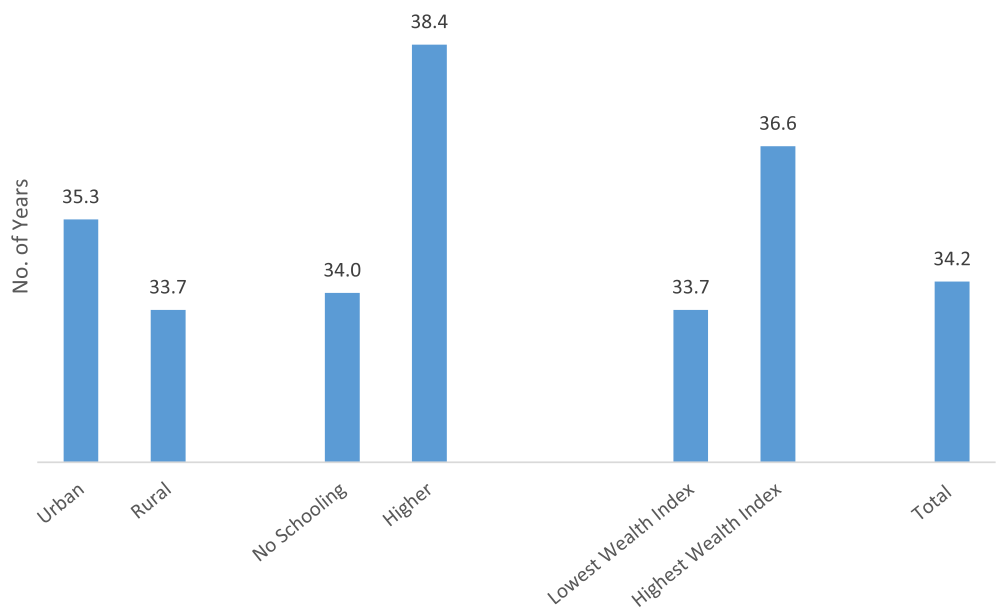

Fig. 2 Socioeconomic contrasts in median age of hysterectomy in India, NFHS (2015-16)

Women who lived in rural areas had an about 1.5 times greater likelihood of having had a hysterectomy as compared with women living in urban areas. Women from the higher wealth quintile households were found to be at a significantly higher risk for hysterectomy as compared with women from the lower wealth quintile households. For example, women from the highest quintile were 2.0 times more likely than women from the lowest quintile to have undergone a hysterectomy. Similarly, women from the second, third, and fourth quintiles were at a significantly higher risk of hysterectomy as compared to women from the lowest quintile.

Women's body mass index was also found to be statistically significantly associated with the likelihood of having undergone a hysterectomy. Women with a BMI more than or equal to $25 \mathrm{~kg} / \mathrm{m}^{2}$ were 1.4 times more prone to have undergone hysterectomy than their counterparts with a BMI less than $25 \mathrm{~kg} / \mathrm{m}^{2}$. Age at first cohabitation (also known as age at consummation of marriage) predicted a negative and a significant association with the odds of having undergone a hysterectomy in the study population. Women who reported their age of first cohabitation at 20 years and above had 55\% lower odds of having undergone hysterectomy than women who reported their first cohabitation at age less than 15 years.

In our analysis, women's parity also came out as a significant predictor of hysterectomy. The study found that women of third and higher parity were 1.9 times more likely to have undergone a hysterectomy compared with nulliparous women. The odds of having had a hysterectomy were $82 \%$ higher for women who had either first or second parity compared with nulliparous women.

Women who lived in the South and East regions, respectively, were about 2.1 and 1.8 times as likely to have undergone a hysterectomy as women in the North region of India. Women who lived in the Central region were also about 1.3 times more likely to report a hysterectomy as compared with women in the North region. In contrast, women in the Northeast region were about 34\% less likely to report having undergone a hysterectomy as compared with women from the North region.

The Omnibus tests shows that the model has significantly improved from the base to the full model at

Table 2 Time since hysterectomy and source where hysterectomy done among women age 30-49, India, NFHS (2015-16)

\begin{tabular}{lll}
\hline State/union territory & Number of women who undergone hysterectomy & Percentage distribution \\
\hline Time since hysterectomy (in years) $^{\mathrm{a}}$ & 6439 & 31.1 \\
$0-3$ & 4750 & 23.0 \\
$4-6$ & 9476 & 45.9 \\
7 and above & & 32.2 \\
Place of hysterectomy & 6687 & 67.8 \\
Public health facilities & 14,061 & 100.0 \\
Private health facilities & 20,761 & \\
All & &
\end{tabular}

${ }^{\mathrm{a}} 96$ women did not report timings of hysterectomy and ${ }^{\mathrm{b}} 13$ women did not report source of hysterectomy in the survey 
Table 3 Adjusted Odds Ratios obtained from the final step from multivariate logistic regression analysis

\begin{tabular}{|c|c|c|c|c|}
\hline \multirow[t]{2}{*}{ Background Characteristics } & \multirow[t]{2}{*}{ Categories } & \multirow[t]{2}{*}{$\operatorname{Exp}(B)$} & \multicolumn{2}{|c|}{$\underline{95 \%} \mathrm{Cl}$ for $\operatorname{EXP}(\mathrm{B})$} \\
\hline & & & Lower & Upper \\
\hline \multirow[t]{4}{*}{ Age } & $30-34$ & & & \\
\hline & $35-39$ & $1.763^{c}$ & 1.675 & 1.855 \\
\hline & $40-44$ & $2.815^{c}$ & 2.680 & 2.957 \\
\hline & $45-49$ & $3.840^{c}$ & 3.658 & 4.031 \\
\hline \multirow[t]{4}{*}{ Women's Education } & No schooling & & & \\
\hline & Primary & $.872^{c}$ & .836 & .909 \\
\hline & Secondary & $.654^{c}$ & .628 & .681 \\
\hline & Higher & $.447^{c}$ & .410 & .486 \\
\hline \multirow[t]{4}{*}{ Caste/tribe } & Scheduled caste & & & \\
\hline & Schedule tribe & $.896^{\mathrm{b}}$ & .839 & .957 \\
\hline & Other backward class & $1.252^{c}$ & 1.202 & 1.304 \\
\hline & Other & $1.203^{c}$ & 1.148 & 1.260 \\
\hline \multirow[t]{6}{*}{ Religion } & Hindu & & & \\
\hline & Muslim & $.708^{c}$ & .673 & .744 \\
\hline & Christian & .980 & .892 & 1.077 \\
\hline & Sikh & $1.173^{\mathrm{a}}$ & 1.035 & 1.331 \\
\hline & Buddhist/neo-Buddhist & $.499^{c}$ & .400 & .622 \\
\hline & Others & .832 & .674 & 1.028 \\
\hline \multirow[t]{2}{*}{ Place of Residence } & Urban & & & \\
\hline & Rural & $1.463^{c}$ & 1.411 & 1.518 \\
\hline \multirow[t]{5}{*}{ Wealth Index } & Lowest & & & \\
\hline & Second & $1.350^{c}$ & 1.281 & 1.423 \\
\hline & Middle & $1.575^{c}$ & 1.492 & 1.662 \\
\hline & Fourth & $1.780^{c}$ & 1.679 & 1.888 \\
\hline & Highest & $2.029^{c}$ & 1.896 & 2.170 \\
\hline \multirow[t]{3}{*}{ Body mass Index } & $\mathrm{BMI}<25 \mathrm{~kg} / \mathrm{m}^{2}$ & & & \\
\hline & $\mathrm{BMl}<25 \mathrm{~kg} / \mathrm{m}^{2}$ & $1.392^{c}$ & 1.348 & 1.438 \\
\hline & $\mathrm{BMI}=$ not available & $1.120^{\mathrm{a}}$ & 1.014 & 1.236 \\
\hline \multirow[t]{3}{*}{ Marital Status } & Currently married & & & \\
\hline & Widow & 1.503 & .726 & 3.114 \\
\hline & Others & 1.196 & .584 & 2.451 \\
\hline \multirow[t]{4}{*}{ Starting Age at First Cohabitation } & Less than 15 & & & \\
\hline & $15-19$ & $.665^{c}$ & .641 & .691 \\
\hline & 20 and above & $.459^{\mathrm{c}}$ & .438 & .480 \\
\hline & Not applicable & $.397^{\mathrm{a}}$ & .192 & .820 \\
\hline \multirow[t]{4}{*}{ Parity } & None & & & \\
\hline & Two-three & $1.818^{c}$ & 1.632 & 2.026 \\
\hline & Three and above & $1.850^{c}$ & 1.660 & 2.062 \\
\hline & North & & & \\
\hline \multirow[t]{4}{*}{ Region } & Central & $1.253^{\mathrm{c}}$ & 1.179 & 1.332 \\
\hline & East & $1.824^{c}$ & 1.715 & 1.939 \\
\hline & Northeast & $.659^{c}$ & .574 & .756 \\
\hline & West & $1.641^{* * *}$ & 1.540 & 1.748 \\
\hline
\end{tabular}


Table 3 Adjusted Odds Ratios obtained from the final step from multivariate logistic regression analysis (Continued)

\begin{tabular}{lllll}
\hline Background Characteristics & Categories & Exp(B) & $\frac{95 \% \text { Cl for EXP(B) }}{\frac{\text { Lower }}{\text { Upper }}}$ \\
\hline & & South & $2.061^{c}$ & 1.946 \\
& Constant & .031 & 2.183
\end{tabular}

${ }^{a} 5 \%$ level of significance; ${ }^{b} 1 \%$ level of significance; ${ }^{c} 0.1 \%$ level of significance

$p<0.000$, and converged with Chi-square at the value of $11,410.59$.

\section{Reasons for which hysterectomy was performed}

The literature suggests that hysterectomy treats a number of conditions and diseases. These include chronic pain, excessive bleeding, endometriosis, pelvic floor prolapse, uterine and cervical cancers, uterine disorders, etc. The NFHS-4 asked all the women who had undergone a hysterectomy the question: "Why was this operation (hysterectomy) preformed?" It was a multiple response category question as there may be more than one reason for resorting to hysterectomy. Table 4 is generated by tabulating these responses from the dataset. The sample size $(\mathrm{N})$ for each state and union territory is provided in the last column of the table.

Table 4 posits that the most frequently reported reason for undergoing hysterectomy at the national level was women suffering from excessive menstrual bleeding/pain (56\%), followed by fibroid/cyst $(20 \%)$. Slightly less than three-fourths of women $(73 \%)$ in Chhattisgarh reported excessive menstrual bleeding/pain as one of the reasons for hysterectomy. Table 4 shows the percentage of women aged 30-49 who reported excessive menstrual bleeding and pain and fibroid/cysts, respectively, as reasons for hysterectomy in different states of India. Among the major states, like Maharashtra (61\%), Karnataka (56\%), Andhra Pradesh (55\%), and Tamil Nadu (51\%), more than 50\% women had undergone hysterectomies because of excessive menstrual bleeding and pain. The percentage of women who had undergone a hysterectomy due to excessive bleeding and pain ranged between $25 \%$ and $50 \%$ in the remaining states of India.

Fibroids /cysts are the second self-reported indications of hysterectomy in India. The percentage of women who reported fibroids /cysts as the cause for their hysterectomies ranged from $2 \%$ in Tripura to the highest of $49 \%$ each in Kerala and Punjab.

Himachal Pradesh (37\%), Jammu and Kashmir (37\%), and Telangana $(34 \%)$ fell in the middle of this range (Table 4).

Nationally, $14 \%$ of women aged 30-49years gave uterine rupture as one of the reasons for their hysterectomy, whereas about $8 \%$ reported that uterine prolapse was one of the reasons for it. Women from Delhi in the North (23\%) and Telangana (22\%) in the South reported uterine rupture as the more frequent reason for hysterectomy than the national average.

It is to be noted that $6 \%$ of women reported that cancer was also one of the reasons for hysterectomy at the national level. The proportion of women reporting cancer as a reason for hysterectomy was the highest among women in Uttar Pradesh (16\%), Chhattisgarh (13\%), and Tamil Nadu (8\%). (Table 4).

Only $9 \%$ of women who reported excessive menstrual bleeding/pan as one of the reasons for hysterectomy also reported suffering from fibroids/cysts before having undergone the surgery (Data not shown). On the other hand, of those women who reported fibroids/cysts as one of the reasons for hysterectomy, nearly a quarter (24\%) reported that they had suffered from excessive bleeding too (Data not shown). Therefore, one can say that excessive menstrual bleeding/pain is not a coexisting condition for hysterectomy among Indian women.

\section{Discussion}

This is the first study in India that provides the prevalence of hysterectomy among women aged 30-49 years from a nationally representative survey at the national, regional and state levels. It also provides social, economic and demographic determinants along with self-reported reasons for undergoing hysterectomy. This paper offers a comprehensive analysis regarding all these critical aspects of hysterectomy in the Indian context. In the western world, the prevalence of hysterectomy ranges from 10 to $20 \%$ among women in the latter half of the reproductive span. However, the findings of this study reveal that six in every 100 women aged 30-49 have had a hysterectomy in India. The prevalence is about 11 per 100 women in the age group $45-49$ years. The study by Prusty, Choithani and Gupta (2018) also found hysterectomy prevalence ranging between 0.2 per to 6.3 per 100 women in the age group $15-49$ years for 21 out of 36 states and UTs of India [8]. If one converts the prevalence among women aged 30-49 into absolute numbers, India will probably turn out to be the largest country in the world having women with such surgeries. Another worrisome factor is the low median age at hysterectomy in India. Our data reveals that the median 
Table 4 Percentage of women (30-49) undergone hysterectomy and reported various reasons for hysterectomy by State/UTS, NFHS(2015-16)

\begin{tabular}{|c|c|c|c|c|c|c|c|c|}
\hline State/union territory & $\begin{array}{l}\text { Excessive menstrual } \\
\text { bleeding/Pain }\end{array}$ & $\begin{array}{l}\text { Fibroids } \\
\text { /Cysts }\end{array}$ & $\begin{array}{l}\text { Uterine disorder } \\
\text { (Rupture) }\end{array}$ & Cancer & $\begin{array}{l}\text { Uterine } \\
\text { prolapse }\end{array}$ & $\begin{array}{l}\text { Severe post-partum } \\
\text { haemorrhage }\end{array}$ & other & $\begin{array}{l}\text { Total } \\
\text { sample (N) }\end{array}$ \\
\hline \multicolumn{9}{|l|}{ North } \\
\hline Chandigarh & 19.8 & 56.4 & 10.6 & 6.9 & 16.7 & 0.0 & 0.0 & 9 \\
\hline Delhi & 44.9 & 21.1 & 22.7 & 5.4 & 3.5 & 2.1 & 6.2 & 115 \\
\hline Haryana & 61.3 & 19.9 & 13.0 & 6.2 & 8.3 & 2.4 & 5.3 & 276 \\
\hline Himachal Pradesh & 32.4 & 37.2 & 14.5 & 1.2 & 3.2 & 4.1 & 12.7 & 85 \\
\hline Jammu \& Kashmir & 43.6 & 36.9 & 19.3 & 1.3 & 7.9 & 3.1 & 4.5 & 170 \\
\hline Punjab & 44.0 & 48.8 & 14.1 & 1.8 & 5.4 & 1.2 & .9 & 397 \\
\hline Rajasthan & 58.5 & 24.6 & 14.0 & 6.8 & 10.7 & 3.4 & 3.0 & 786 \\
\hline Uttarakhand & 48.0 & 24.0 & 10.3 & 7.0 & 12.2 & 3.6 & 8.3 & 117 \\
\hline \multicolumn{9}{|l|}{ Central } \\
\hline Chhattisgarh & 73.1 & 15.7 & 11.7 & 3.4 & 5.6 & 2.5 & 4.4 & 299 \\
\hline Madhya Pradesh & 61.8 & 17.3 & 13.6 & 5.5 & 6.5 & 3.6 & 7.8 & 1218 \\
\hline Uttar Pradesh & 53.1 & 15.5 & 10.5 & 16.0 & 7.6 & 3.7 & 10.2 & 2251 \\
\hline \multicolumn{9}{|l|}{ East } \\
\hline Bihar & 54.6 & 9.1 & 18.0 & 7.0 & 18.1 & 5.5 & 5.8 & 2705 \\
\hline Jharkhand & 54.4 & 15.7 & 19.2 & 4.8 & 9.8 & 7.2 & 7.1 & 371 \\
\hline Odisha & 47.0 & 4.8 & 9.4 & 4.2 & 8.9 & 5.7 & 24.9 & 506 \\
\hline West Bengal & 40.0 & 25.8 & 10.0 & 1.5 & 6.3 & 3.2 & 18.1 & 1102 \\
\hline \multicolumn{9}{|l|}{ Northeast } \\
\hline Arunachal Pradesh & 28.6 & 2.9 & 13.4 & 4.0 & 14.0 & 9.9 & 29.2 & 10 \\
\hline Assam & 54.3 & 4.0 & 11.8 & 5.1 & 4.4 & 9.8 & 15.0 & 157 \\
\hline Manipur & 39.4 & 30.6 & 18.8 & 2.5 & 11.1 & 5.4 & 4.6 & 19 \\
\hline Meghalaya & 21.1 & 21.5 & 17.7 & 1.1 & 10.7 & 10.4 & 23.4 & 17 \\
\hline Mizoram & 11.8 & 39.4 & 12.2 & 22.3 & 2.1 & 2.4 & 16.7 & 6 \\
\hline Nagaland & 37.4 & 19.1 & 12.4 & 8.3 & 4.0 & 5.0 & 15.0 & 12 \\
\hline Sikkim & 59.6 & 15.4 & 17.1 & 1.5 & 5.3 & 2.5 & 3.5 & 4 \\
\hline Tripura & 34.9 & 1.5 & 14.6 & 2.7 & 4.7 & 14.0 & 32.0 & 27 \\
\hline \multicolumn{9}{|l|}{ West } \\
\hline Dadra \& Nagar Haveli & 64.0 & 12.1 & 3.9 & 0.0 & 11.3 & 0.0 & 20.5 & 6 \\
\hline Daman \& Diu & 45.2 & 6.6 & 5.1 & 0.0 & 4.0 & 0.0 & 39.1 & 2 \\
\hline Goa & 44.8 & 28.0 & 13.1 & 0.0 & 5.5 & 1.4 & 7.2 & 21 \\
\hline Gujarat & 49.6 & 28.2 & 13.6 & 1.6 & 7.0 & 2.4 & 9.0 & 1339 \\
\hline Maharashtra & 69.2 & 13.0 & 10.2 & 3.9 & 6.5 & 3.2 & 5.7 & 1654 \\
\hline \multicolumn{9}{|l|}{ South } \\
\hline Andaman \& Nicobar Islands & 64.5 & 10.4 & 9.8 & 0.0 & 4.9 & 1.5 & 19.1 & 4 \\
\hline Andhra Pradesh & 63.8 & 22.5 & 17.0 & 2.4 & 3.6 & 1.3 & 0.9 & 2556 \\
\hline Karnataka & 64.4 & 19.2 & 10.0 & 3.6 & 5.3 & 3.8 & 4.1 & 968 \\
\hline Kerala & 39.9 & 49.3 & 10.9 & .7 & 5.9 & 3.0 & 1.0 & 349 \\
\hline Lakshadweep & - & - & - & - & - & - & - & 1 \\
\hline Puducherry & 78.1 & 26.2 & 2.5 & 1.8 & 2.9 & 0.0 & 1.4 & 13 \\
\hline Tamil Nadu & 55.5 & 12.3 & 8.7 & 8.2 & 6.1 & 3.3 & 11.0 & 1622 \\
\hline Telangana & 48.3 & 34.4 & 22.2 & 2.4 & 4.2 & 1.7 & 3.0 & 1567 \\
\hline India & 55.6 & 19.8 & 13.9 & 5.5 & 7.8 & 3.4 & 7.1 & 20,761 \\
\hline
\end{tabular}


age at hysterectomy is as low as 34 years at the national level and lower still among women belonging to the rural and lowest wealth quintile settings. This means half of the hysterectomies in India are done before women hit their mid-thirties. Similar results were obtained in a study by Desai et al. (2016), who estimated 36 years of median age at hysterectomy for women in a low income setting in the state of Gujarat [5]. This can have a huge impact on the women's socio-psychological and physical health on account of the adverse effects of the long exposure of undergoing a hysterectomy at an early age [24].

Age is a significant and clear predictor for women undergoing hysterectomy. This may be attributable to more and more women being advised by doctors to undergo the surgery or to women themselves choosing to get rid of their health problems after achieving the desired number of children, all of whom have survived up to a certain age. Women with no schooling, those living in rural areas, those belonging to higher wealth quintiles, those with $\mathrm{BMI}>=25 \mathrm{~kg} / \mathrm{m}^{2}$, those belonging to other castes, those of higher parity, those with a low age at first cohabitation, and those from eastern and southern regions are more likely to undergo hysterectomy. It is highly probable that women with no schooling and those from a rural background may have had a hysterectomy due to an infection or uterus-related morbidities. On the other hand, women belonging to well-off households (more likely from better off households and $\left.\mathrm{BMI}>=25 \mathrm{~kg} / \mathrm{m}^{2}\right)$ may have had it because they were more likely to be able to afford the costly procedure of hysterectomy. Here it is important to mention that more than two-thirds (68\%) of hysterectomies are reported to have been done in private health settings, where a woman's family has to bear nearly the entire financial burden caused due to the procedure. The study by Desai, Sinha and Mahal [5] supports our finding that rural women are more likely to go for hysterectomies. The prevalence of hysterectomy is also somewhat linked with the low age at first birth and high number of births and untreated reproductive morbidities, as cited by Govil [4]. These are typical features of reproduction among rural women and women with no schooling in India. Generally, less educated women are less aware of reproductive health and hygiene [23]. Awareness about health check-ups and health-seeking behaviour are also low among uneducated women and those from poor socioeconomic backgrounds. These factors can potentially delay, or cause the women to avoid, seeking treatment at the initial stages of a reproductive health problem [25]. Most women do not seek treatment at the early stages of reproductive health problems because they perceive them to be normal for women. Medical treatments are sometimes regarded as an unnecessary intervention in the women's reproductive health system [11].

The prevalence of hysterectomies in the states of Andhra Pradesh (16\%), Telangana (14\%), Bihar (11\%), and Gujarat (8\%) was found to be relatively higher than in the other states. The study by Prusty, Choithani and Gupta [8] too showed that Andhra Pradesh (6\%), Telangana (5.5\%), and Karnataka (3\%) had a relatively higher prevalence than the remaining 18 states. They, however, found the prevalence in Andhra Pradesh and Telangana to be much lower than what our study has estimated. This discrepancy may be explained on the grounds that this study used data from the NFHS-4, which had developed a full battery of questions related to hysterectomy and had provided comprehensive training to field investigators on this medical procedure. This may have aided women in responding more clearly to the questions related to hysterectomy.

Telangana was carved out of Andhra Pradesh and, therefore, shares similar sociodemographic, cultural, and health practices. The NFHS-4 shows that about twothirds of women in the reproductive age group in Andhra Pradesh and about 57\% in Telangana were overweight or obese [23]. The fact that hysterectomy is associated with overweight and obesity and that women face early marriage and early initiation into childbearing in these two states could be why the prevalence of hysterectomy was found to be higher in these two states. Bihar is one of the most backward states in terms of socioeconomic development; generally, women there are less aware of reproductive health problems and the treatment options. It is also one of the least urbanised states of India. The higher prevalence of hysterectomy in Bihar is likely the outcome of poor access to public health infrastructure in rural areas in the state, the result being delay in treatment seeking for reproductive health problems and hysterectomy being used as the last resort to deal with them. Gujarat is one of the more developed states of India, where a high proportion of women belong to the high wealth quintile and where there is a good presence of the private health sector, which might partially lead to a high risk for hysterectomy. However, one should investigate whether the age group 40-49 is overrepresented since a high prevalence of hysterectomy was observed in this group, particularly in the state of Gujarat.

The leading self-reported causes of hysterectomy are excessive menstrual bleeding/pain (56\%), followed by presence of fibroids/cysts (20\%) and uterine ruptures (14\%). Since the question had multiple answers, some of the reasons might be overlapping. However, most of the hospital based studies from other countries show that fibroids $(73 \%$ in Hong Kong, 65\% in India, 60\% in USA, 
33\% in Pakistan, and 23\% in South Africa), followed by prolapse remain the leading cause for hysterectomy [2629]. A regional pattern emerged in this study - excessive menstrual bleeding or pain was the most common cause in Haryana, Madhya Pradesh, Chhattisgarh, Maharashtra, Karnataka, Andaman and Nicobar Islands, and Andhra Pradesh. On the other hand, fibroids or cysts were the most common cause of hysterectomy in Chandigarh, Punjab, and Kerala. Uttar Pradesh must draw the immediate attention of policy makers as cancer was the second most frequently reported reason for hysterectomy.

\section{Conclusion}

This paper concludes that the likelihood of a woman undergoing hysterectomy increases with age, wealth quintile, and parity. On the other hand, it decreases with increasing years of schooling and age at first cohabitation. Sikh, rural, obese (BMI $>=35 \mathrm{~kg} / \mathrm{m}^{2}$ ) women, and those who reside in the south region possess a higher risk for hysterectomy than their counterparts in the respective reference groups. The other important contribution of this paper is providing reasons for hysterectomy from the population based nationally representative dataset. It concludes that the most frequent reason for undergoing hysterectomy was excessive menstrual bleeding/pain, followed by the presence of fibroid/cyst. There were large variations across the states and the UTs in reporting the reasons for undergoing hysterectomy. This paper also finds that the median age at hysterectomy is much lower among Indian women.

The conclusion clearly indicates the need to spread general awareness regarding reproductive health issues, treatment seeking, reducing high fertility, increasing age at first marriage, and cohabitation. Obese women should be advised to go for regular screening of reproductive health so that appropriate treatment other than hysterectomy can be tried first. More specific interventions are required to deal with the reproductive health problems reported by women as reasons for hysterectomy. Reproductive health program managers should devise state specific strategies to enable women to seek treatment at the initial stage so that unnecessary hysterectomies can be avoided. At the policy level, there is a pressing need to improve both the access to and the quality of reproductive health care services in public health facilities so as to reduce the growing dependency on hysterectomies in treating reproductive health problems. Specific intervention programs for the early screening, identification, and treatment of women's sexual and reproductive health problems need to be formulated. The national health program on women's health and gender mainstreaming, included in the recent
National Health Policy [30], talks about enhanced provisions for reproductive morbidities and health needs of women beyond the reproductive age group (40+). However, neither this health policy nor the draft National Policy for Women [31] makes any mention of hysterectomy emerging as a public health issue. It is important, therefore, that the health and financial consequences of hysterectomy on women's lives be addressed as part of comprehensive strategies for the screening, necessity and after-effects of hysterectomy while designing the national health program for women. The policy documents should also expand the intended age group since many hysterectomies are performed on women below the age of 40 years. There is a need to devise strategies to deal with the burden of unnecessary hysterectomies by developing some regulatory or ethical clearance mechanism especially for private sector providers. These concerns have also been reported by many studies in the past $[18,19,32,33]$. In addition to causing multiple health consequences, hysterectomy may also lead to catastrophic health expenditure and may push a family into poverty due to heavy dependence on the private health sector, especially it is not protected under any health insurance scheme. Even when a family avails treatment in the public sector, women are likely to face financial and health implications.

The policy makers need to be cautioned about the probable scenario where the number of unnecessary hysterectomies may go up because of the availability of laparoscopic technology [34] and cashless protection under the Ayushman Bharat health program [35]. Women may avoid hysterectomy because of the fear of open surgery that requires a longer hospitalization and healing time or because of the lack of financial resources. But access to the new laparoscopic hysterectomy that it is being promoted as a minimal or non-invasive procedure and that requires a much shorter hospital stay or healing time may mitigate those fears. The entitlements under the Ayushman Bharat scheme may also be misused in case of women from the poor sociodemographic strata. Therefore, implementing authorities must ensure some kind of regulatory mechanism while making payments to private providers for these women.

\section{Limitations of the study}

The present study has limitations since the NFHS-4 does not provide data on the costs incurred or the financial loss faced by women or their families due to hysterectomy. We suggest that the future rounds of NFHS collect such important policy-relevant information from each woman who has undergone a hysterectomy. Data should also be collected on its different aspects like whose decision it was to go for the 
surgery, for how long the woman had been suffering from health problems due to which hysterectomy had to be done, where and for how long the woman had been undergoing treatment before she resorted to the operation, and what the sources of finance were. The NFHS-4 dataset does not provide information as to whether a woman was operated through the laparoscopic technique or through the usual surgical procedure, or whether it was abdominal or vaginal, or whether a woman had any side effect of hysterectomy. It also does not provide any information on whether the hysterectomy was done after all other treatment methods had been exhausted.

As for the reasons of hysterectomy, no interpretations could be made for the state of Goa, for UTs other than Delhi, and for Northeast states except Assam and Tripura due to the small sample size (less than 25 cases). The future NFHS round may consider larger sample of women from these states and UTs. The above information would be extremely useful in developing strategies for quality service provisions to those women who genuinely need to undergo hysterectomy in India.

\begin{abstract}
Abbreviations
BMI: Body mass index; CEBs: Census enumeration blocks; Cl: Confidence interval; GIS: Geographical information system; HPE: Histopathological examination; IIPS: International institute for population sciences; IUDs: Intrauterine devices; NFHS: National family health survey; NGOs: Nongovernmental organization; OR: Odds ratio; PPS: Probability proportion to size; SPSS: Statistical package for social sciences; UTs: Union territories
\end{abstract}

\section{Acknowledgements}

Authors acknowledge the contribution of Ms. Shailja Thakur for thorough language editing and Dr. Akash Wankhede and Ms. G. Sudha for helping in preparing dataset and Maps for the analysis.

\section{Authors' contributions}

CS conceived the study, performed the statistical analysis, drafting the writeup and making interpretations of the results and drawing the conclusion. BP was involved in conceptualizing the study, performing the statistical analysis, coordination and reviewing Maps. AS participated in conceptualization of the study and reviewing the earlier drafts of the manuscript and statistical analysis. All authors read and approved the final manuscript.

\section{Funding}

No funding was available for preparing this manuscript.

\section{Availability of data and materials}

The data for this research is available to the public on DHS measures website. Any individual can register and easily obtained data in electronic version from the following website https://dhsprogram.com/data/new-userregistration.cfm

\section{Ethics approval and consent to participate}

"Not applicable" as the used dataset is secondary source for the present paper. However, in our knowledge Ethical approval was obtained from the IIPS Ethical Review Board (No. IRB/NFHS-4/01_1/2015).

\section{Consent for publication}

"Not applicable".

\section{Competing interests}

Authors declare no conflicts of interest as well as competing interest.

\section{Author details}

${ }^{1}$ Department of Fertility Studies, International Institute for Population Sciences (IIPS), Mumbai, India. ${ }^{2}$ Department of Population Policies and Programmes, International Institute for Population Sciences (IIPS), Mumbai, India. ${ }^{3}$ Department of Public Health and Mortality Studies, International Institute for Population Sciences (IIPS), Mumbai, India.

Received: 14 March 2019 Accepted: 24 July 2019

Published online: 02 August 2019

\section{References}

1. Hysterectomy, https://www.webmd.com/women/guide/hysterectomy\#1. Accessed on 10 May 2019.

2. Brett KM, Madans JH. Hysterectomy use: the correspondence between selfreports and hospital records. Am J Public Health. 1994;84(10):1653-5.

3. Dharmalingam A, Pool I, Dickson J. Biosocial determinants of hysterectomy in New Zealand. Am J Public Health. 2000;90(9):1455.

4. Govil D. An insight into reproductive ageing of India women (Unpublished doctoral dissertation). Mumbai: International Institute for Population Sciences; 2005.

5. Desai $S$, Sinha T, Mahal A. Prevalence of hysterectomy among rural and urban women with and without health insurance in Gujarat, India. Reprod Health Matters. 2011;19(37):42-51.

6. Desai S, Campbell OM, Sinha T, Mahal A, Cousens S. Incidence and determinants of hysterectomy in a low-income setting in Gujarat. India Health Policy Plan. 2016:32(1):68-78.

7. Huque S, Roberts I, Fawole B, Chaudhri R, Arulkumaran S, Shakur-Still H. Risk factors for peripartum hysterectomy among women with postpartum haemorrhage: analysis of data from the WOMAN trial. BMC Pregnancy Childbirth. 2018;18:186. https://doi.org/10.1186/s12884-018-1829-7 Accessed 9 May 2019.

8. Prusty RK, Choithani C, Gupta SD. Predictor of hysterectomy among 15-49 years in India. Reprod Health. 2018;15(3). https://doi.org/10.1186/s12978-01 7-0445-8 Accessed 22 Feb 2019.

9. Whiteman MK, Kuklina E, Hillis SD, Jamieson DJ, Meikle SF, Posner SF, Marchbanks PA. Incidence and determinants of peripartum hysterectomy. Obstet Gynecol. 2006;108(6):1486-92.

10. Liu F, Pan Y, Liang Y, Zhang C, Deng Q, Li X, Ning T. The epidemiological profile of hysterectomy in rural Chinese women: a population-based study. BMJ Open. 2017;7(6):e015351.

11. Singh A, Arora AK. Why hysterectomy rate are lower in India. Indian J Community. 2008;33(3):196.

12. Radha K, Devi GP, Chandrasekharan PA, Swathi P, Radha G. Epidemiology of hysterectomy-a cross sectional study among Piligrims of Tirumala. IOSR J Dent Med Sci (IOSR-JDMS). 2015;1:14):1-5.

13. Verma D, Verma ML. Trends of hysterectomy in the rural tertiary level teaching hospitals in northern India. Indian J Obstet Gynaecol Res. 2016;3(3): 212-5.

14. Pandey D, Sehgal K, Saxena A, Hebbar S, Nambiar J, Bhat RG. An audit of indications, complications, and justification of hysterectomies at a teaching hospital in India. Int J Reprod Med 2014. https://doi.org/10.1155/2014/2792 73. Accessed 24 Feb 2019.

15. Uikey P, Wankhede TM, Tajne MP. The route of hysterectomy: a comparative study between abdominal hysterectomy $(\mathrm{AH})$, non-descent vaginal hysterectomy (NDVH), and laparoscopic assisted vaginal hysterectomy (LAVH). Int J Reprod Contracept Obstet Gynecol. 2018 Oct;7(10):4022-8.

16. McGivering J. The Indian women pushed into hysterectomies. The British Broadcasting Corporation (BBC). 2013 Available at https://www.bbc.com/ news/magazine-21297606. [Accessed 13 May 2019].

17. Chaudhuri M. Women's groups and fertility experts campaign to reduce prevalence of hysterectomy in India. BMJ. 2013;347:f7551. https://doi.org/1 0.1136/bmj.f7551.

18. Acharya SK. Womb, womenhood and medical ethics: concern about rising hysterectomy cases in India. J FamPlannReprod Health Care. 2017;43(2):1656.

19. Xavier T, Vasan A, Vijayakumar S. Instilling fear makes good business sense: unwarranted hysterectomies in Karnataka. Indian J Med Ethics. 2017;2(1):4955. https://doi.org/10.20529/IJME.2017.010 Accessed 10 May 2019. NS.

20. Meulen J. van der. Increasing use of laproscopic hysterectomy: we need to talk about outcomes. Int J Obstet Gynaecol. 2019;126(6):803. https://doi. org/10.1111/1471-0528.15643 Access on 12 May 2019. 
21. Verma D, Singh P, Kulshrestha R. Analysis of histopathological examination of the hysterectomy specimens in a north Indian teaching institute. Int J Res Med Sci. 2016;4(11):4753-8. https://doi.org/10.18203/2320-6012.ijrms2 0163761.

22. Palmer JR, Rao RS, Adams-Campbell LL, Rosenberg L. Correlates of hysterectomy among African-American women. Am J Epidemiol. 1999; 150(12):1309-15.

23. International Institute for Population Sciences (IIPS) and ICF. National Family Health Survey (NFHS-4), 2015-16: India. Mumbai: IIPS; 2017.

24. Bachman GA. Psychosexual aspects of hysterectomy. Womens Health Issues. 1990;1(1):41-9.

25. Sahoo M, Som M, Pradhan J. Perceived barriers in accessing the reproductive health care services in Odisha. Indian J Community Health. 2017;29(3):229-38.

26. Broder MS, Kanouse DE, Mittman BS, Bernstein SJ. The appropriateness of recommendations for hysterectomy. Obstet Gynaecol. 2000;95(2):199-205.

27. Butt JL, Jeffery ST, Van Der Spuy ZM. An audit of indications and complications associated with elective hysterectomy at a public service hospital in South Africa. Int J Gynaecol Obstet. 2012;116(2):112-6.

28. Leung PL, Tsang SW, Yuen PM. An audit on hysterectomy for benign diseases in public hospitals in Hong Kong. Hong Kong Med J. 2007;13(3): 187-93.

29. Qamar-Ur-Nisa HMF, Shaikh TA, Memon Z. Hysterectomies: an audit at a tertiary care hospital. The ProfMed J. 2011;18(1):46-50.

30. Government of India. National Health Policy. Ministry of Health and Family Welfare: 2017 Available at: https://mohfw.gov.in/sites/default/files/9147562 941489753121.pdf [Accessed 12 Feb 2019].

31. Government of India. National Policy for women 2016: articulating a vision for empowering women (draft), Ministry of women and child development (MoWCD), 2016, Available at: https://wcd.nic.in/sites/default/files/ draftnationalpolicyforwomen2016_0.pdf. Accessed 10 May 2019.

32. Understanding reasons for rising number of hysterectomies in India National Consultation 12th August 2013. Health Watch, UNFPA, HRLN and Prayas. Available at http://www.prayaschittor.org/pdf/Hysterectomy-report. pdf. Accessed 22 May 2019

33. Dragisic KG, Milad MP. Sexual functioning and patient expectations of sexual functioning after hysterectomy. Am J Obstet Gynecol. 2004;190(5): $1416-8$.

34. Madhvani, K, Curnow T, Carpenter T. Route of hysterectomy: a retrospective, cohort study in English NHS hospitals from 2011 to 2017. Int J Obstet Gynaecol 2019;126(6):795-802 https://doi.org/10.1111/1471-0528.15539. Access 11 May 2019.

35. National Health Authority 2019. https://www.pmjay.gov.in/about-pmjay. Accessed on 15 May 2019

\section{Publisher's Note}

Springer Nature remains neutral with regard to jurisdictional claims in published maps and institutional affiliations.

Ready to submit your research? Choose BMC and benefit from:

- fast, convenient online submission

- thorough peer review by experienced researchers in your field

- rapid publication on acceptance

- support for research data, including large and complex data types

- gold Open Access which fosters wider collaboration and increased citations

- maximum visibility for your research: over $100 \mathrm{M}$ website views per year

At BMC, research is always in progress.

Learn more biomedcentral.com/submissions 